Response to Semetsky

\title{
Thinking of(f) the Deep End: Semetsky and the Complicated Conversation
}

\author{
JAMES ANTHONY WHITSON \\ School of Education, University of Delaware, USA
}

\begin{abstract}
An astonishing array of theoretical discourses appear woven together seamlessly in Semetsky's rationale for using Tarot practice as a tool for education, drawing from theoretical traditions that range from Jung's and Pauli's theories of archetypes and synchronicity, to chaos and complexity or complex systems theories, to C.S. Peirce's semiotic pragmaticism, to natural law, to hermeneutics, and to the phenomenology of human subjects and life-worlds. This response considers some of those traditions in relation to each other, with particular concern for issues of language, meaning, knowledge, thinking, and human agency. The priority of Semetsky's concern for individuation and integration of the human subject within their meaningful life-world is observed as having paramount importance for her project.
\end{abstract}

The discourse of curriculum scholarship is now widely characterized as "complicated conversation" (Pinar, 2004). Semetsky (2008) opens vast possibilities for complicated conversation, even as she succeeds in "simplifying" the complexity of what she's writing about. 


\section{Effing the Ineffable}

In the introduction to his Tractatus, Wittgenstein (1921/2001) famously wrote, "The whole sense of the book might be summed up in the following words: what can be said at all can be said clearly, and what we cannot talk about we must pass over in silence." As he explained:

Thus the aim of the book is to draw a limit to thought, or rather-not to thought, but to the expression of thoughts: for in order to be able to draw a limit to thought, we should have to find both sides of the limit thinkable (i.e. we should have to be able to think what cannot be thought).

It will therefore only be in language that the limit can be drawn, and what lies on the other side of the limit will simply be nonsense. (pp. 3-4)

Near the end of the Tractatus, in Proposition 6.522, it is acknowledged that "There are, indeed, things that cannot be put into words. They make themselves manifest. They are what is mystical" (p. 89). He concludes, again famously, that "What we cannot speak about we must pass over in silence"' (p. 89).

Semetsky is not afraid to transgress the limitations on thought and expression asserted here by Wittgenstein. Instead, she uses language to explain Tarot reading as a medium for "making manifest" matters of inestimable interest and importance that might otherwise be relegated to a realm of the ineffably mystical.

In Proposition 6.54, Wittgenstein explains: “My propositions serve as elucidations in the following way: anyone who understands me eventually recognizes them as nonsensical ... “ (p. 89). To simplify a distinction that's important for the Tractatus (but not so much for us), nonsensical (unsinnig) expressions are not utterly devoid of sense (Sinn); rather, they have enough "sense" or meaning to say something that does not make good logical sense, according to what's recognized as good logical sense in the Tractatus. Semetsky's paper would not have been called "nonsense" of this kind. For Wittgenstein of the Tractatus, Semetsky's paper is not "nonsensical" (unsinnig), but rather "senseless" (sinnloss)-i.e., it doesn't have the kind of sense required for an expression even to say something meaningful enough that it could be evaluated as either sensical or nonsensical. As he explains in Proposition 6.53:

The correct method in philosophy would really be the following: to say nothing except what can be said, i.e. propositions of natural science-i.e. something that has nothing to do with philosophy-and then, whenever someone else wanted to say something metaphysical, to demonstrate to him that he had failed to give a meaning to certain signs in his propositions. (p. 89)

Not only Semetsky's paper, but the Tarot practice that it presents to us, refuses to be bound by such limitations on the use of language for bringing into consciousness realities that seem to defy linguistic articulation. But this refusal is not a matter of unruly waywardness: it is, rather, a sophisticated and explicit position within at least some of the systems such as "the I Ching, Tarot, and astrology" that Semetsky tells us (quoting 
Samuels, 1985, p. 266) are acknowledged by post-Jungians "as important resources in analysis" (Semetsky, p. 69).

In an accretion to the I Ching, for example, Confucius is accredited with saying that “writing does not exhaust speaking; speaking does not exhaust meaning" (书不尽言, 言 不尽意). But does that mean there's no way to apprehend the meaning of the sages? The Master explained that "the sages put in place images (xiang) to reveal meaning, and established the hexagrams to make manifest all states of affairs" (圣人立象以尽意, 设卦 以尽情伪). ${ }^{1}$

While I Ching, Tarot, and like traditions are not silent about the deep realms of reality that the Tractatus tells us are utterly (but unutterably) beyond the reach of sensible language (sensible, that is, as the kind of fully defined propositional language that the Vienna Circle positivists imagined as the proper kind of language for the natural sciences), it is not as if they don't know any better than to not keep silent. It is rather that, appreciating full well the limitations of that kind language-of language limited to completely defined and specified propositions - these traditions have given rise to other ways of "effing [what could otherwise be regarded as] the ineffable."

\section{Re-meaning Meaning}

In order to "know thyself... and others," Semetsky argues cogently that we need socially mediated access to realms of meaning that the Tractatus would relegate to a silent mysticism. This requires mediative practices using signs and language that go far beyond the kind of idealized formal language recognized as having sense, and capable of making good sense, in the Tractatus.

As we have seen, the I-Ching tradition explicitly recognizes this problematic in the quest for profound meaning. But if we think of "meaning" as something fundamentally different from what is recognized in the Tractatus, then what is it that we mean by meaning? Semetsky asks, "Indeed, whence meanings?" (p. 66); but, prior to that, we might ask "and what is/are meaning(s), anyway?"

This has actually been an issue of some tension (and contention) in the history of Semetsky's manuscript, itself. Where the article now reads:

Full of such implicit (that is, "existing" only in potential) - and in need of mediation meanings, pictures can be used to make abductive inferences, so as to create an actual narrative as an explicit meaning for the images ... (p. 67, underlining added),

the underlined text was added in response to a reviewer who asked, "no text is 'full of meanings' - meanings are produced by readers aren't they?" Where the text now reads

During readings, a particular constellation of images in the Tarot layout may indicate to

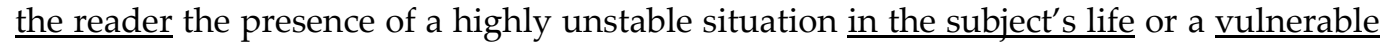
state of mind ... (p. 72),

\footnotetext{
${ }^{1}$ My translation, for this context, informed by the notes and modern Chinese renderings in Song (2000, p. 342). Each of the key terms in the ancient Chinese text is open to a range of interpretations, as debated by Chinese scholars over more than two millennia.
} 
the reviewer had asked, "is this attributing agency to the layout?" The underlined text below was added to, and the strike-through text deleted from, the earlier draft:

During the interpretive process, the pictures ereate a narrative are being narrated thereby creating an adventure story describing an experimental journey through concrete life experiences. (p. 73).

Here, the reviewer had asked, "Surely it is the interpreter who creates a narrative, not the pictures?"

We should note, first, what this shows about the great care and thoroughness with which this article has been written, and reviewed and edited. Also, the added language of adventure story and of journey through experience helps articulate Semetsky's project within the discourse of Curriculum Theory, recognizing curriculum as not the map (e.g., lesson plans, or national and provincial guidelines, etc.) and not the territory (e.g., the disciplines or subject-matter contents), but the person's journey over the course of their own formative experience (Whitson, in press-b).

The reviewer raises seriously problematic points concerning meaning and agency. The revisions might make her paper more comfortable to readers who would privilege human agency, and reader-generated meaning. But if Semetsky's prior formulations suggest agency and meaning as being more independent of human actors and readers, it would seem these formulations may actually be closer to Jung's theory of archetypal synchronicity, as well as to (at least some forms of) complex systems theory. Of course, I'm not suggesting any slavish fidelity to either of those orientations. The point, rather, is to take advantage of the opportunities for dialogue presented by contrasting points of view, rather than to lose those opportunities as the cost of blurring over real differences.

Jung (1960) characterized synchronicity as "a meaningful coincidence of two or more events, where something other than the probability of chance is involved" (p. 520, Jung's emphasis). He saw the "simultaneous occurrence of two meaningfully but not causally connected events" as "an essential criterion" for synchronicity, "in contrast with 'synchronism,' which simply means the simultaneous occurrence of two events" (p. 441). As Jung elaborates:

Synchronicity therefore means the simultaneous occurrence of a certain psychic state with one or more external events which appear as meaningful parallels to the momentary subjective state-and, in some cases, vice versa. (p. 441)

The external events (such as the Tarot layout or the I Ching hexagram) appear "as meaningful parallels" to the psychic or subjective state, but to whom do they so appear? Perhaps not immediately (i.e., without mediation) to the person whose psychic state is meaningfully parallel to the external event. In Jung's psychoanalysis, mediation by the analyst may be essential, since, "in general, ... the patient has an insuperable tendency to interpret the results of the analytical investigation of his material obstinately in terms of his pathogenic attitude" (p. 259).

Semetsky explains that the Tarot reader is

an experienced person who has developed her sensitivity and intuition so as to secure readings of a high reliability. A reader functions as a "bilingual" interpreter converting 
the pictorial language of the unconscious into verbal expressions and facilitating the trans-formation of in-formation into consciousness. (p. 65, Semetsky's emphasis)

The Tarot reader, like the analyst, may be essential for discovery of meaning that in some way is presented in the layout itself-meaning that is not essentially a product of interpretation by the reader, or by the subject of the reading.

In his foreword to the English translation of Richard Wilhelm's edition of the $I$ Ching, Jung (1950/1967) explained that

... synchronicity takes the coincidence of events in space and time as meaning something more than mere chance, namely, a peculiar interdependence of objective events among themselves as well as with the subjective (psychic) states of the observer or observers.

The ancient Chinese mind contemplates the cosmos in a way comparable to that of the modern physicist, who cannot deny that his model of the world is a decidedly psychophysical structure. The microphysical event includes the observer just as much as the reality underlying the I Ching comprises subjective, i.e., psychic conditions in the totality of the momentary situation. (p. xxiv)

In other words, while the observer's psychic state is one of the co-incidents within the total momentary situation, the meaning is inherent in the coincidence itself, and is not just produced by the observer.

Jung relates how, in writing his foreword, he cast a hexagram to ask the I Ching for "its judgment about its present situation, i.e., my intention to present it to the Western mind" (p. xxvi). Explaining that "in accordance with the way my question was phrased, the text of the hexagram must be regarded as though the I Ching itself were the speaking person," he reads the text appended to the hexagram he cast as the I Ching "testifying concerning itself" (p. xxvi): "The I Ching is complaining, as it were, that its excellent qualities go unrecognized and hence lie fallow. It comforts itself with the hope that it is about to regain recognition" (p. xxvii), and, ultimately,

The I Ching expresses itself here as being not only well satisfied but indeed very optimistic. One can only await further events and in the meantime remain content with the pleasant conclusion that the I Ching approves of the new edition. (p. xxxi)

While there's plenty of room for more ironic readings of what Jung was up to in this foreword, it would seem that we should not be overly hasty in transposing "meaning," or Jung's idea of "meaning," into the terms of what might be for us a more comfortably modern reader-response kind of theory. 
Main (1997) observes that Jung

... appears to recognize not one but several kinds of meaning that can adhere to synchronicities ... . Aziz, for example, has identified four levels of meaning referred to by Jung at different times. These are: (1) simply the fact of two or more events paralleling one another (the paralleling is by virtue of a shared content or meaning); (2) the emotional charge or 'numinosity' attending the synchronicity (a source of nonrational meaning); (3) the significance of the synchronicity interpreted subjectively, from the point of view of the experiencer's personal needs and goals; and (4) the significance of the synchronicity objectively, as the expression of archetypal meaning which is transcendental to human consciousness ... (Main, 1997, p. 28)

Among these four types of meaning, "numinosity" might seem to be the farthest stretch beyond "meaning" as significant "content." But some degree of confirmation might be found in this uncanny coincidence: The I Ching passage on words and meaning quoted above in the section on "effing the ineffable" actually culminates in numinosity. Here is a more complete translation:

The Master said: "The sages put in place images to reveal meaning; and established the hexagrams to make manifest all states of affairs; they attached phrases to the hexagrams to exhaust the I Ching's speaking; change flowed throughout to exhaust its benefits; they drummed it and danced it to exhaust the numinosity." 2

Semetsky asks, "Indeed, whence meanings?" In answer to this question, she quotes Herbert Simon saying "a symbol is simply the pattern, made of any substance whatsoever that is used to denote, or point to, some other symbol, or object or relation between objects. The thing it points to is called its meaning" (Simon, 1995, p. 31), and she adds: "Full of such implicit (that is, 'existing' only in potential) - and in need of mediation - meanings, pictures can be used to make abductive inferences, so as to create an actual narrative as an explicit meaning for the images" (pp. 66-67). It seems to me that Simon and Semetsky are saying very different things, and that Semetsky is the one who gets it right.

"The thing it points to" is the referent, not the sense (i.e., the Bedeutung, not the Sinn), and hence is less than what we mean by "meaning." Semetsky's use of mediation and abduction in her explanation invokes the semiotic approach of C. S. Peirce, whom she also uses in this paper making other points. With Peirce, we understand meaning not as a thing that's pointed to, and not as content contained in or conveyed by what Simon would call "symbols." "Meaning" is best not used as a noun at all, but as a verb: Meaning is not something that signs have; meaning is, rather, what signs do-with "signs" understood as active mediated/mediating triadic relations in which the mediating term potentiates the events ("interpretants") in which meaning will be going

\footnotetext{
${ }^{2}$ This is (again) my translation, so my use of "numinosity" might seem suspiciously convenient for this context. The clause “鼓之 [drummed it] 舞之 [danced it] 以尽神” is translated (more verbosely) by Richard Lynn as "They made a drum of it, made a dance of it, and so exhausted the potential of its numinous power" (Classic of Changes, 1994, p. 67). This translation is based on the I Ching Commentary by Wang $\mathrm{Bi}$ (226-249 CE), which was unknown to Jung or Wilhelm; so this is an independently corroborative source.
} 
on. It seems to me that Peirce's take on meaning can do justice to what Jung says about $I$ Ching, and what Semetsky says about Tarot-indeed, all the way to numinosity. Simon, on the other hand, is confined within his systems-theoretical approach to information and cognition.

Peirce's pragmatic approach to meaning leads us to ask about the consequences of our conceptions for the conduct of our inquiry. In this case, the inquiry in question (not just our own inquiry, but that of teachers and their students) is all about self-knowledge. This is also Jung's (1950/1967) ultimate concern with the I Ching, which he says "insists upon self-knowledge throughout" (p. xxxiii). "Clearly, the method aims at selfknowledge" (xxxiv), Jung observes, and he concludes that "for lovers of self-knowledge, of wisdom - if there be such - it seems to be the right book" (p. xxxix).

\section{Gnowing the connatural}

In the quest for self-knowledge, we return to Semetsky's ultimate concern for how "knowing oneself ... and others" can be achieved through the practice of Tarot. As we paused before to consider meaning, we may now pause to consider knowing.

Semetsky recognizes from the outset that Tarot "is usually considered esoteric and ipso facto unscientific" (p. 63). We see two levels of the problematic here: On one level, scientific knowledge is in principle accessible to the public generally, and in that sense is not esoteric. This pertains to the kind of knowing about natural phenomena that can be achieved through scientific practice. On another level, knowledge about science-what it is and how it works - is also publicly accessible, as might be contrasted with knowledge about Tarot, which might be thought of as more esoteric knowledge. "By addressing this [Tarot] practice in the framework of complexity theory," Semetsky tells us, she "will demystify the often misunderstood realm of Tarot and will assert its value for education as one of the means to "Know Thyself'" (p. 63). We see both levels here: a non-esoteric elucidation of Tarot, and then Tarot practice as a means of non-esoteric knowing about selves.

While these might seem to be problems of methodology and epistemology, Semetsky goes directly to more fundamental problems of ontology. The "dualistic split" she's challenging is overcome, she tells us, in the image on the culminating Tarot card called "The World," or "The Universe":

This picture is a symbol of the Self that finally overcomes the dualistic split between itself and the material world and embodies a greater numinous, spiritual, dimension. In Dewey's words, the Universe is precisely the "name for the totality of conditions with which the self is connected" (Dewey 1934/Hickman and Alexander, 1998, 1, p. 407). (Semetsky, p. 73).

We can see this "dualistic split" reflected in the difference in language used for signifying supposedly two different kinds of knowledge. As Dewey (1933/1998) himself noted, for example, "Most languages have two sets of words ... $\gamma v \omega v \alpha$ เ [gnönai] and $\varepsilon เ \delta \varepsilon ́ v \alpha \iota$ [eidenai] in Greek; noscere and scire in Latin; kennen and wissen in German; connaître and savoir in French ..." (p. 139; cf. Buck et al., 2000, pp. 81-85). What is taken to 
be "scientific" knowledge (scire / wissen, / savoir / eidenai) is knowledge of things taken apart-indeed, the Indo-European root for "science" (and, in Latin, scire) is also the root for "scissors" (see skei- in the Appendix on Indo-European Roots, in the American Heritage Dictionary of the English Language).

This "scissors" sense of knowledge dominates not only positive science disciplines, but often academia in general, and even the curriculum in schools. This is far narrower than what we often recognize in relationships of knowing outside of the school context (e.g., the way two people know each other, or the way a musician knows a favorite composition). This is a more familiar sense of knowing, marked by the "con-" ("with") in connaître.

A key difference seems to be the difference between separation, or knowledge by discernment (as in cutting things apart with scissors) versus conjoining (as suggested by the cog- prefix in cognoscere, or the con- in connaitre). Dewey (1949, p. 186, making a somewhat different point) once called attention to the contrastive relationship between the words "discern" and "concern" - which suggests the possibility that "scientic" knowledge as in scire/savoir could be referred to as "discerning knowledge," by contrast with cognostic or "concerning knowledge" as in connaitre or cognoscere.

Scientic or discerning knowledge presumes a dualistic split between the knowing subject, and the object being known. Cognostic or concerning knowledge relies on a commonality of nature shared by the knower and the known, as in connaisance (lit., having birth together). To the extent that we are connatural with things encountered in our world, partaking with them in a commonly shared nature, we can know them through a multiplicity of diverse semiosic interactions. Scientic knowledge becomes our only hope, however, when we seek knowledge of things whose natures are so alien to ours ("alio-natural," to coin a phrase, rather than connatural), that the only knowledge we can have of them is through such non-cognostic instruments as particle accelerators, or Maxwell's equations.

According to Kant, we must accept as epistemologically necessary that "things as such" cannot be knowable, by us, just as they are, in themselves, because our way of knowing necessarily conditions what we know in ways that make our knowledge something other than a knowledge purely of those things, as they are, in themselves.

When Semetsky notes that "we desperately need to develop alternative methods in an effort to continue what Charles Sanders Peirce called the search for the ultimate interpretant of reality" (p. 76), it might seem that this is a call for realism, as against idealism. In actuality, however, Peirce's own position differs from both Realism and Idealism. In The Impact on Philosophy of Semiotics: The Quasi-Error of the External World with a Dialogue between a "Semiotist" and a "Realist," Deely (2003) explains how a Peircean understanding differs from "realism," and is better understood as a "semiotist" approach. The "quasi-error of the external world" is one source of the problem with Realism: It presumes (as Kant did) an external world that is not connatural with us. The semiotist approach, to the contrary, recognizes constant semiosic intercourse between 
humans and our world, in which each participates in the formation of the other. ${ }^{3}$

Where Realism and Idealism both spring from presumptions of a great gap between the real world and a realm of ideas, Peirce understood ideas as signs, within a world largely made up of sign activity, perfusing all the world, both of nature and of culture, alike. One does not understand nature by conceiving of it as something "real" as if reality were something (anything) apart from the ideality of semiosis.

There is another problem with "reality," which I see as also related to the Peircean objection. In a "comparison of three approaches to an understanding of 'what is actual': modern science, Husserlian phenomenology, and Tibetan Buddhist Dzog Chen" (Hut, 1999, p. 391), astrophysicist Piet Hut of the Institute for Advanced Study in Princeton, N.J. explains:

What are world views views of? An obvious answer would be 'reality', but that word is already slanted to a particular class of world views. The root 're', of the Latin res, or thing, suggest that things are at the base of everything. However, many world views are more dynamic, and do not necessarily base themselves upon things or objects as being most fundamental. Therefore, a more general word would be 'actuality', rather than 'reality'. Whether or not 'what is actual' can be explained in terms of things will be left open. (p. 395)

In terms of Peirce's semiotics, the world (including human Being) is formed in sign activity, i.e., in the action of signs as triadic relations, and as nets and webs of such relations, in which ourselves and other things, themselves, are taking form. Taking "act" as the root of "actual," I use "actualist" where Deely uses "semiotist." While these are similar alternatives to "realist," the word "actualist" is less opaque to people who don't know semiotics. Either way, the recognition of active form-taking is conducive to consciousness of curriculum, as essentially concerned with the course of (actively semiosic) experience in which human being takes form (cf. Whitson, 2007).

These reflections help us to appreciate all the more the importance of Semetsky's explanation of how the "World" picture in Tarot "is a symbol of the Self that finally overcomes the dualistic split between itself and the material world and embodies a greater numinous, spiritual, dimension" (p. 73) and the passages she quotes there from Dewey (1934), recognizing that "the unification of the self ... cannot be attained in terms of itself. The self is always directed toward something beyond itself and so its own

\footnotetext{
${ }^{3}$ On "formation," see footnote 10, p. 98 below. Deely has done more than anyone else I know of to draw from Peirce's work what I see as its most important breakthroughs, which Deely (2001) presents as inaugurating the post-modern age in human thought. While it is possible to read Peirce's semiotics as a theory for communication, or for cognition, science, and epistemology, Deely's work has brought me to appreciate the more far-reaching ontological implications, with semiosis being understood as the activity of signs in which being comes to form anew, and new being comes to form. In Whitson (2007) I argue for the importance for education of curriculum consciousness informed-i.e., "in*formed," not "info*d" (see fn. 10) - by this kind of semiotic understanding.

People sometimes have trouble getting into Deely's writing. I think it's more than worthwhile, although I can't tell how much more difficult it would be for me to read without my two years of high school Latin. Readers of this journal might want to start with Bains (2006), which introduces Deely's approach to Peirce within a framework that also features Deleuze, Deleuze \& Guattari, and Maturana and Varela. Deely, Petrilli, and Ponzio (2005) is also likely to be of interest to many readers here.
} 
unification depends upon the idea of the integration of the shifting scenes of the world into that imaginative totality we call the Universe." We can't know ourselves unless we know ourselves as being-in-the-world; but the world is knowable by us cognistically (and not just scientistically) on the basis of our shared connaturality.

\section{Cogent "Nonsense"?}

Should it be said that I am using a word whose meaning I don't know, and so am talking nonsense [Unsinn]? -Say what you choose, so long as it does not prevent you from seeing the facts. (Wittgenstein, Philosophical Investigations, 1953/2001, p. 32)

And do I always talk with very definite purpose?-And is what I say meaningless [sinnloss] because I don't? (Wittgenstein, 1953/2001, p. 161)

We noted at the outset how Semetsky's richly provocative and cogent treatise could be written only in violation of what Wittgenstein proscribed in the Tractatus as "nonsensical" or "senseless" language use. In the Tractatus, Wittgenstein drew boundaries around "sensical" and "meaningful" language as consisting of nothing but scientic propositions, as in the "propositions of natural science." By the time of his Philosophical Investigations, Wittgenstein knew better: He now understood sense and meaning in terms of how language is used-for varied purposes (even when those purposes aren't "very definite"), within a broad variety of "language games." 4

So sense and meaning in Semetsky's discourse must be construed in terms of her own purposes, her own language games. Earlier we noted two levels of purpose in Semetsky's paper, as she explains that "by addressing this [Tarot] practice in the framework of complexity theory, the paper will de-mystify the often misunderstood realm of Tarot and will assert its value for education as one of the means to 'Know Thyself'" (p. 63). At once, we notice purposes belonging to two distinct language games: the language game of Tarot practice itself, which promises self-knowledge, and the language game of theory-writing, for the sake of demystifying Tarot, for the sake of rendering Tarot reasonable in terms of complex systems theory, and, we might suppose, for the sake of making contributions to the formulation of complexity theory, as well.

I wonder: In what ways, and to what extent, are these purposes and these two language games related to each other? For example, we might wonder: To what extent should the perceived value of Tarot depend on its articulation in the language of complexity? Would Semetsky's own personal belief in the value of Tarot (which presumably has another basis in her own experience) be any less, for example, without

\footnotetext{
${ }^{4}$ I cannot resist suspecting that the drastic changes in Wittgenstein's understanding of such things as language, thought, and learning were provoked, in no small degree, by reflecting on his experience as an elementary school teacher in the years between his writing of the Tractatus and the Philosophical Investigations. Consider this, for example, as one exhibit:

If you were unable to say that the word "till" could be both a verb and a conjunction, or to construct sentences in which it was now the one and now the other, you would not be able to manage simple schoolroom exercises. But a schoolboy is not asked to conceive the word in one way or another out of any context, or to report how he has conceived it. (Wittgenstein, 1953/2001, p. 149)
} 
that articulation? If there are people who can testify as to the value of Tarot in their own lives and experience, doesn't that supply sufficient rationale for trying it, with or without the complexity theory? And if there were not people who could testify that they have found it to be of value, how much would the complexity theory help in persuading people of its value?

(In the week that I was first reading Jung and von Franz in preparation for this paper, I myself was struck with how my dreams at night seemed to have been affected. Not having actually experienced Tarot or used the I Ching, and not having much interest or belief in Jungian archetypes, I can easily believe that Tarot practice with an experienced and insightful reader could be impressively effective in bringing about the kinds of self-knowledge and transformation that Semetsky writes about.)

Even Jung (1950/1967) said in his Foreword to the I Ching, "The less one thinks about the theory of the I Ching, the more soundly one sleeps" (p. xxxix).

Consider acupuncture: It seems likely that the use of acupuncture in the Westincluding its use by mainstream practitioners of scientific medicine-has grown on the basis of its perceived effectiveness, apart from theories about how it works. Doctors and patients who believe that it does work need not be discouraged if they remain skeptical about the theory-whether the traditional $q i\left(c h^{\prime} i\right)$ theory, or more modern-science theories of an analgesic mechanism. On the other hand, even belief in one of those theories is not likely to motivate the use of acupuncture in the absence of belief in its effectiveness.

As Jung (1950/1967) says in his foreword to the I Ching:

My position in these matters is pragmatic, and the great disciplines that have taught me the practical usefulness of this viewpoint are psychotherapy and medical psychology. Probably in no other field do we have to reckon with so many unknown quantities, and nowhere else do we become more accustomed to adopting methods that work even though for a long time we may not know why they work. Unexpected cures may arise from questionable therapies and unexpected failures from allegedly reliable methods. ( $p$. xxxiv)

There is a difference though, it seems to me, between acupuncture and Tarot or the I Ching. In the case of acupuncture, the patient can judge whether it is working or not without any idea of how it might be working. A patient seeking relief from lower back pain can judge whether the pain is gone or not without thinking about how the treatment works. The same could not be said of Tarot or the I Ching, unless these were being used merely as techniques for fortune-telling. As mere superstitious fortunetelling, it would be possible to judge whether the I Ching or Tarot reading did or did not yield accurate predictions-much as in judging whether acupuncture treatment did or did not reduce or eliminate the pain-without thought as to how the practice may have worked. But that's different from the kind of practices Jung and Semetsky are describing. As Jung (1950/1967) tells us,

The I Ching insists upon self-knowledge throughout. The method by which this is to be achieved is open to every kind of misuse, and is therefore not for the frivolous-minded and immature; nor is it for intellectualists and rationalists. ... Clearly the method aims at 
self-knowledge, though at all times it has also been put to superstitious use. (pp. xxxiiixxxiv)

In a lecture to the C. G. Jung Institute, Marie-Louise von Franz (1980), a coworker with Jung for many years, elaborated on this difference:

What is important in China, as Jung also pointed out in his essay called "Synchronicity: An Acausal Connecting Principle," is that the Chinese did not get stuck, like many other primitive civilizations do, into using divination methods only to predict the futurewhether for instance one should marry or not. (p. 10)

In this stage divination cannot evolve and become differentiated; it remains a kind of primitive guessing technique, trying to guess the future by some technical means. ... it is not built into the Weltanschauung and therefore remains a kind of undeveloped primitive practice, a ritual game, so to speak, which we tend not to integrate into our conscious view of reality. (pp. 10-11)

Semetsky explains Tarot as a medium not only for self-knowledge, but for transformation of the self as integrated and individuated within the life-world of the human subjectand with the encompassing Weltanschauung or world-view represented most explicitly in the cards themselves:

The circular shape on the [Tarot] World picture represents a continuum, that is, the never-ending search for meanings in the changing circumstances of experience. "The World" represents the ideally individuated Self, that is, an integrated personality as inseparable from its life-world. (p. 73)

Thoughts, emotions, hopes, fears, interpersonal relationships, intrapsychic conflicts, immediate environment, desires and wishes - in short, the whole phenomenology of the subject's life-world, of which however the subject might not yet be aware at a conscious level, is being projected into the layout - the symbolic representation of the said lifeworld. But the subject becomes aware of oneself because of the possibility of transforming itself and, in a self-organizing manner, being able to perceive its own responses as new stimuli in the self-referential relation, the significance of which was anticipated as long ago as 1925 by Russian psychologist and educator Lev Vygotsky. (p. 74)

So this is not like acupuncture, which can be judged to be working or not working even without any insight into how it does its work. Unlike acupuncture, the working of Tarot reading necessarily enlists the active agency of the human subject, who must have an (at least implicit) understanding of the work that she is doing with Tarot.

If the work of Tarot is not the work of fortune-telling, but is rather (as Semetsky tells us) the work of knowing self (and knowing others), and of self-(trans-)formative practice, it would seem that the subject could not judge whether Tarot is "working" or "not working" as a matter of whether it is telling or not telling fortunes accurately. But is that necessarily the case? Could it not still be possible that a subject could feel satisfied with the results that they are getting because of Tarot's efficacy in the manner Semetsky describes, although consciously they are still thinking of it only as a matter of fortune-telling? Can it be that with Tarot-as with acupuncture-it is possible to make 
judgments based on efficacy alone, without an inkling as to how the treatment or the practice works?

I think not. Tarot, as Semetsky describes it for us, is a practice, and not just a treatment (such as acupuncture). In acupuncture treatment, as in pharmaceutical treatment, the drugs or the needles can work their magic on the patient even if the patient is not conscious of what's happening. The patient may be just that: a patient, not an agent. As Semetsky describes it, Tarot is a practice, not a treatment. The subject in Tarot is a practitioner-along with the reader-and cannot be just a patient. The selftransformative and knowing practice that Semetsky describes will not work if the subject is participating as merely a patient, or a passive recipient, of fortune-telling.

Does this mean, then, that the subject needs to understand the theory of what it means for Tarot to "work," in order to take her part in the doing of that work? Does this mean, for example, that the subject needs to know about self-individuation, about integration of her personality within her life-world, and about "the whole phenomenology of the subject's life-world"?

I think that Wittgenstein ${ }^{5}$ can help us here. The subject needs to know the languagegame of Tarot in the way that a player knows how to play the game. Just as we can say that a native speaker of French "knows the language" even without the abstracted, systematically conceptualized understanding of French that a linguist might have (even a linguist who cannot speak French like a native can), so too can (and must) Tarot subjects know the language game of Tarot practice-in which they are actively and mindfully participating as agents in the integration of their personalities within their life-worlds-even if they've never even heard the word "phenomenology."

But how far must this knowledge go? Must it include any kind of knowledge or belief in Jung's archetypes, or synchronicity? With reference to the I Ching, Jung (1950/1967) wrote, "my argument as outlined above [i.e., his theory of archetypes and synchronicity] has of course never entered a Chinese mind" (p. xxv). Yet, presumably Chinese use of the I Ching was just as effective before Jung's explanation as it is now, and remains as effective today as ever for those who've never heard of archetypes or synchronicity.

For Tarot to be more than fortune-telling, and to do the kind of work Semetsky describes, users may need to have enough awareness of that work to play their part. As with the I Ching, however, it may be that those satisfied with Tarot's efficacy would use it regardless of whether they believe or even know about Jung's theory; and an understanding of Jung's theory seems unlikely to persuade someone to use Tarot if they do not find it effective through the kind of experience that historically has not depended on that theory. ${ }^{6}$

\footnotetext{
${ }^{5}$ I mean, of course, the later Wittgenstein - he of the Philosophical Investigations, with the benefit of elementary school teaching experience.

${ }^{6}$ It is clear from Jung's writing, in his Foreword and elsewhere, that he did find use of the I Ching undeniably effective, before he ever tried to explain that effectiveness in terms of archetypes and synchronicity - a concept developed initially in his attempt to account for the I Ching. Of course, someone might be motivated by Jung's theory to give Tarot a try, even if they only find the theory interesting or plausible, but have not yet come to believe in archetypal synchronicity.
} 


\section{Semetsky writes:}

It is the practice of Tarot readings that this paper posits in terms of critical lessons embedded in our experience. By addressing this practice in the framework of complexity theory, the paper will de-mystify the often misunderstood realm of Tarot and will assert its value for education as one of the means to "Know Thyself"; thus it can be considered an educational tool contributing to our learning and, respectively, the evolution of the human mind situated in the larger, both cultural and natural, context. (pp. 63-64)

It would seem that if the value of Tarot for education can be asserted "in terms of critical lessons embedded in our experience," then its use as an educational tool may be warranted, with or without belief in archetypes or synchronicity; and belief in Jung's theory is likely not to be sufficient if the practice is not found effective in experience.

\section{Theories and practices}

But what, then, about the framework of complexity theory? To see how systems theory fits in with the other approaches under our consideration, it may be helpful to arrange them as in Table 1.

\begin{tabular}{|c|c|c|c|c|}
\hline practice & & theory & possible interests & $\begin{array}{l}\text { relevant } \\
\text { theorists }\end{array}$ \\
\hline pan-synthesis & $\mathrm{D}$ & $\begin{array}{c}\text { complexity/ } \\
\text { complex systems } \\
\text { theory }\end{array}$ & $\begin{array}{c}\text { autopoiesis } \\
\text { escape from determinism } \\
\text { cybernetic control }\end{array}$ & $\begin{array}{l}\text { Luhmann } \\
\text { Simon }\end{array}$ \\
\hline $\begin{array}{l}\text { hyper- } \\
\text { mundane } \\
\text { practice }\end{array}$ & $\mathrm{C}$ & $\begin{array}{c}\text { archetypal } \\
\text { synchronicity; } \\
\text { quantum } \\
\text { psycho-physics }\end{array}$ & $\begin{array}{l}\text { demystifying } \\
\text { the uncanny; } \\
\text { fulfilling dreams }\end{array}$ & $\begin{array}{l}\text { Jung } \\
\text { Pauli } \\
\text { Stapp }\end{array}$ \\
\hline $\begin{array}{l}\text { mundane } \\
\text { practice }\end{array}$ & B & life-world 7 theory & $\begin{array}{l}\text { knowledge of self/others } \\
\text { in personal \& social self-formation } \\
\text { (i.e., in Curriculum Vitæ, or } \\
\text { "curriculum of life") } \\
\text { personal individuation } \\
\text { \& life-world integration }\end{array}$ & $\begin{array}{c}\text { Semetsky } \\
\text { (Habermas) }^{8}\end{array}$ \\
\hline $\begin{array}{l}\text { fortune- } \\
\text { telling }\end{array}$ & A & magic & $\begin{array}{l}\text { dispelling uncertainty } \\
\text { gaining control }\end{array}$ & $(\text { von Franz })^{9}$ \\
\hline
\end{tabular}

Table 1: Theoretical frameworks for consideration of Semetsky's explanation of Tarot

\footnotetext{
${ }^{7}$ Semetsky hyphenates life-world; Habermas does not. I construe them as referring to the same thing. I will hyphenate or not based on whether I'm discussing Semetsky or Habermas.

${ }^{8}$ Habermas is referenced for his commitment to life-world theory, which he argues for against the universalist claims of Luhmann's complex systems theory. This is not meant to suggest that Habermas would support adoption of Tarot practice on the basis of this theory.

${ }^{9}$ Von Franz is referenced here for articulating the difference between this level of divination and more theoretically informed practices.
} 
I have introduced this schematization in the course of questioning the extent to which a decision to adopt Tarot reading may depend, or not depend, on the theoretical explanations being offered. I have suggested that if Tarot practice is found effective, then it may be adopted even by those who do not believe in archetypes or synchronicity; and that belief in Jung's theory might not make a difference for someone who does not find Tarot reading to be effective. This might sound like I'm suggesting a crude untheoretical empiricism. This schema may help show the contrast between the untheoretical empiricism of magical fortune-telling, versus the kind of practice Semetsky has described, which is necessarily informed - in active practice, even if implicitly-by life-world theory. Although Semetsky's rationale for Tarot practice spans the gamut of non-magical approaches, she is referenced here for life-world theory because it is this framework she invokes directly in her explanation of what it is that Tarot does; and her use of the injunction to "know thyself (and others)" gives a priority to this purpose over other possible interests.

\section{The Mundane and the Hyper-mundane}

Jung himself did not take up use of the I Ching after being convinced by his theory of archetypes and synchronicity. It was quite the other way around. Jung developed his idea of synchronicity while trying to make sense of what he felt from his experience was the undeniable efficacy of the I Ching and other "paranormal" practices. Nobel physicist Wolfgang Pauli was also convinced by personal experiences (notably, his dreams, which he shared with Jung) that these sprung from a fundament of reality that was at once psychic and physical. Both men, working together over many years, were attempting to formulate a psycho-physical theory that would be adequate to this fundamentally psychophysical reality (see, for example, Zabriskie, 2001).

Jung wrote about all sorts of uncanny events, involving use of astrology, the I Ching, and a wide variety of other excursions into the paranormal, and he worked to formulate a theory that would demystify these uncanny phenomena. This work included the interpretation of dreams that were fulfilling for the dreamers. In another sense, the invention of a new science for psychophysical exploration was itself something that Pauli and Jung yearned for over decades of their work together, and the theory of archetypal synchronicity was their best effort to fulfill that dream.

Jung and Pauli both saw uncertainty at the quantum level as a key for understanding acausal (but potentially meaningful) coincidences at the level of reality we encounter in our daily lives. More fundamental than the mundane world of experience as we normally understand it, they sought to make sense of a hypermundane reality: not really a different world from the one we live in every day, but that very same world, to be newly understood in the full dimensions of its hyper-mundane reality.

Zabriskie (2001) quotes complexity theorist and Nobel physicist Murray Gell-Mann (discoverer of the quark) as making comparable arguments for the ramifications of micro-physical or quantum-level events for outcomes on the macro-physical level of mundane experience, when he notes that "A law of geology, biology, or human 
psychology may stem from one or more amplified quantum events, each of which could have turned out differently" (Zabriskie, 2001, p. xliv). It is not clear, however, how far Gell-Mann would go along with Jung and Pauli in their embrace of "psychophysical monism."

It is Gell-Mann who is credited with the term "quantum flapdoodle," which is used dismissively for things like The Secret (Byrne, 2006), or What tue \#\$* Do $\omega \Sigma(k) \pi o w$ !? (Arntz, Chasse, Hoffman, \& Vicente, 2004; Arntz, Chasse, \& Vicente, 2005), that pitch the idea that certain principles of quantum mechanics have macro ramifications, such that our minds have the psychic power to control physical reality at our own macro level.

In his fascinating book, The quark and the jaguar: adventures in the simple and the complex (1994), Gell-Mann has a chapter on "Quantum Mechanics and Flapdoodle" (c. 12, pp. 167-176) which demonstrates the fallacy in extrapolating similarities from uncertainty at the quantum level to phenomena at the macro-physical level. Jeffrey Mishlove (Gell-Mann \& Mishlove, 1998) began an interview (posted at williamjames.com) with this characterization of the book:

In your book The Quark and the Jaguar you are looking at the relationship between the most fundamental and simple known physical units and some of the most complex adaptive systems that exist, from human beings to galaxies, and you find, I believe, similarities. If we look at a jaguar we can see qualities that are reminiscent or evocative of what we might see if we could see a quark.

In response, Gell-Mann offered this correction:

Well, I would say it a little bit differently from that. What I try to do in the book is to trace the chain of relationships running from elementary particles, fundamental building blocks of matter everywhere in the universe, such as quarks, all the way to complex entities, and in particular complex adaptive system like jaguars. And it's not so much similarities but the relationship between them that I explore.

In his chapter on "What is Fundamental" Gell-Mann (1994, c. 9, pp. 107-120) discusses the problem of reductionism-the ideological or research-programmatic reduction of disparate levels of reality to a "fundamental" level, such that (for example) instead of seeing biological ecosystems as operating on the basis of principles that cannot be reduced to principles of basic physics, not only biology, but even psychology, linguistics, and sociology (etc.) are all seen as (ideally and in principle) reducible to physics.

Posing the question in specific historical and institutional terms, Gell-Mann asks

Why does so little research in psychology go on at Caltech today? Granted, the school is small and can't do everything. But why so little evolutionary biology?

And he ventures this by way of explanation:

If a subject is considered too descriptive and phenomenological, not yet having reached the stage where mechanisms can be studied, our faculty regards it as insufficiently "scientific." (1994, p. 118)

He wonders whether Darwin, in his time, would have been invited to join the Caltech faculty. 
We recall Semetsky's explanation that "this paper introduces an interpretive, evaluative, practice as a specific method, which is usually considered esoteric and ipso facto unscientific" (p. 63). Semetsky is proposing mechanisms. For Gell-Mann, the important thing for being "scientific" is not a matter of whether the phenomena can be explained by principles and mechanisms of the most basic levels of reality. Instead, rather, even as we develop "staircases" between levels, and "bridges" across disciplines (or sub-disciplines) on the same level, it is essential for science to attend to any level of reality in terms of the principles of actuality at that level.

At odds with Gell-Mann's sage approach, it seems to me, is the example of Henry Stapp, who soon after finishing his doctorate went to work with Pauli shortly before Pauli's death. Stapp shares with Jung and Pauli a belief in a fundamental psychophysical reality, in which quantum physics holds the key to phenomena now understood as indivisibly both psychological and physical, and at all levels of reality. In Mindful universe: quantum mechanics and the participating observer, he writes:

The aim of this book is to describe the development of this revised conceptualization of the connection between our minds and our brains, and the consequent revision of the role of human consciousness in the unfolding of reality. This revision in our understanding of ourselves and our place in nature infuses the subject with a significance that extends far beyond the narrowly construed boundaries of science. These changes penetrate to the heart of important sociological and philosophical issues. (Stapp, 2007, p. 4)

Stapp argues that before the quantum revolution, the "scientific" vision converted human beings "from sparks of divine creative power, endowed with free will, to mechanical automata-to cogs in a giant machine that grinds inexorably along a preordained path in the grip of a blind causal process" (p. 5; see also pp. 139-143).

Semetsky quotes Stapp's assertion that "if causal anomalies actually do appear then ... we have been offered a glimpse of the deeper reality" (Stapp, 2003, p. 183, quoted by Semetsky on p. 76, n. 9). This is what I refer to in Table 1 as the realm of "hypermundane" practice, contrasted with mundane practice situated in the life-world as described by social theorists.

Stapp posits "causal anomalies" at the quantum level as a basis for believing in free will and moral responsibility at the personal and social levels:

[The classical or pre-quantum, "scientific"] material picture of human beings erodes not only the religious roots of moral values but the entire notion of personal responsibility. Each of us is asserted to be a mechanical extension of what existed prior to his or her birth. Over that earlier situation one has no control. Hence for what emerges, preordained, from that prior state one can bear no responsibility.

This conception of man undermines the foundation of rational moral philosophy, and science is doubly culpable: It not only erodes the foundations of earlier value systems, but also acts to strip man of any vision of himself and his place in the universe that could be the rational basis for an elevated set of values. (Stapp, 2007, p. 5; see also pp. 139-143) 
Quantum physics, he tells us, has brought about a "radical change," which swept away the meaningless billiard-ball universe, and replaced it with a universe in which we human beings, by means of our value-based intentional efforts, can make a difference first in our own behaviors, thence in the social matrix in which we are imbedded, and eventually in the entire physical reality that sustains our streams of conscious experiences. (p. 6)

Stapp claims that "quantum mechanics is more understandable than classical mechanics because it is more deeply in line with our common sense ideas about our role in nature than the 'automaton' notion promulgated by classical physics" (p. 7). In the terms we developed earlier, he is arguing that we are able to know things in the world as being "connatural" with us because the physical world itself, when understood as the hypermundane "deeper" psycho-physical reality, is fundamentally made up of the same "psychophysical building blocks" (pp. 96-98) that at once make up both mind and matter.

But is it really true that our free will and our capacity for moral responsibility depend on indeterminacy at the quantum level? Or that our ability to have knowledge of our world and of our place in the world (and hence to "know ourselves ... and others") depends on quantum indeterminacy, or on an understanding of the world as something made up of "psychophysical building blocks" based on causal indeterminacy at the quantum level?

Stapp's theses are not required for a belief in human freedom and responsibility. Nor do they coincide as he contends they do with ordinary common sense. People ordinarily believe in freedom and responsibility without believing that these things are rooted in causal indeterminacy from the quantum level extending thence to the macrophysical and macro-social. Stapp seems to think that his theses are necessary because, without them, we are left with nothing else but strict, mechanical, billiard-ball causal determinacy. He apparently is simply unaware of semiotic and social theories that account for how freedom, responsibility, and our knowledge of ourselves, others, and our world is possible at the scale of human beings, in our human life-worlds - without being due in any way to causal indeterminacy at the quantum level.

\section{Semiotics, Social Theory, and Pan-Synthetic Systems Theory}

This is not the place to attempt an adequate recounting of these semiotic and social theories. It will have to suffice, for now, to give a couple indications:

First, we understand with semiotics how sign activity makes possible our knowledge of ourselves and others within connatural life-worlds. Through mediating signs, the forms belonging to the make-up of one thing (physical or more purely formal, like a word, idea, or thought) or person participate in the formation of another thing or person. This is how we and our life-worlds are constituted; hence our connaturality and knowability. This is rooted in the formal possibilities of sign activity. Although quantum 
reality may be pertinent to the electronic or neurological conveyance of info ${ }^{*}$ ation $^{10}$ in which some sign activity is carried out, those processes are merely incidental to the in*formation of one person's thinking by another person's new idea. In some cases (e.g., weather forecasting) the sign activity may include chaotic physical processes; but even here the quantum indeterminacy of the mechanical substrate of these processes is not pertinent to the in*formation of the forecast through the semiosis, or the sign-activity.

Second, at the sociological level, we turn to Habermas. Habermas (e.g., 1985/1987) is very much concerned with the possibilities for such things as knowledge, truth, freedom, and responsibility which he sees as rooted in the life-world of mundane human practices. He sees language as an essential medium for realizing these possibilities, and he understands language as something that is generated and sustained at the social level, in communicative practice, not something that is made up out of "psychophysical building blocks," first in the psyches of individuals, and only after that in their societies (cf. Stapp's "universe in which we human beings, by means of our value-based intentional efforts, can make a difference first in our own behaviors, thence in the social matrix in which we are imbedded" (Stapp, 2007, p. 6)).

With Habermas, we may now turn our attention to the level of complex systems theory. Since Semetsky posits the efficacy of Tarot practice most directly at the level of the life-world, we have reason to be concerned about what Habermas (1985/1987) identifies as the tendency for "the "undercomplex' lifeworld" to be separated out "as an indigestible residue" by "the tireless shredding machine of reconceptualization" in systems theories such as that of Niklas Luhmann (Habermas, 1985/1987, p. 354). Habermas is not criticizing systems theory itself, within its proper domains of reference. What he finds both wrong and dangerous are the universalizing claims that not only ignore, but threaten to annihilate the lifeworld. He notes how

... for Luhmann the lifeworld now has already lost all significance in the functionally differentiated societies of the modern world. What disappears from both perspectives [those of Marx and Luhmann] is the mutual interpenetration and opposition of system and lifeworld imperatives, which explains the double-front character of societal modernization. (p. 355)

Habermas cites Luhman's position that whoever clings to "the premises of classical humanism" and "seeks to represent a concern for humanity by means of them has therefore to emerge as an opponent of systems theory's claim to universality"

\footnotetext{
${ }^{10}$ In Whitson (in press-a), I argue that education suffers from the loss of an earlier sense of "information," rooted in ideas of formation that were at the core of earlier conceptions of education. This sense is preserved in European languages in which cognates of "formation" are often used (e.g., when "teacher formation" (la formation des enseignants) is said in French where we would say "teacher education" in the United States), or homologous words like Bildung in German. We see this sense in Semetsky's reference to Tarot as a tool for self-transformation. Having lost this sense, the word "information" is now used almost exclusively in the sense of bits that can carry signals, etc., as in cybernetics or "information theory," such as are used by Luhmann, Dennett, etc. "Information" in this sense can be shortened to just "info," which does not work with "information" in the older sense. I have taken to differentiating these two senses as "info*mation" vs. "in*formation."
} 
(Habermas, 1985/1987, p. 377, quoting Luhmann, 1984, pp. 288, 92). As Habermas points out,

To the degree that systems theory does not merely make its specific disciplinary contribution within the system of the sciences but also penetrates the lifeworld with its claim to universality, it replaces metaphysical background convictions with metabiological ones. (p. 385)

Instead of treating lifeworld problems as if they were just systems-related steering problems, Habermas insists on facing such problems as matters of "building up restraining barriers for the exchanges between system and lifeworld and of building in sensors for the exchanges between lifeworld and system" (pp. 363-364).

Instead of reducing lifeworld to classical physics, or reducing it to psycho-physics, it is reduced in Luhmann's universalistic systems theory to a model based on "cybernetics and biology" (p. 369). Although Tarot presumably is not something of interest to Habermas himself, his critique of universalistic systems theory suggests the threat it poses to the life-world that Semetsky describes as the place where Tarot does its work. It is reassuring that Semetsky recognizes so clearly the priority of the life-world for the practice that she's advocating. What remains for us to see is the articulation of the "sensors" and "restraining barriers" for exchanges between lifeworlds and the systems that environ them.

\section{Meaning and Agency (Redux)}

This returns us to issues of meaning and human agency that were raised earlier by a reviewer of Semetsky's paper. When these concerns were raised before, we noted that Jung does in fact speak of agency by the I Ching itself, and that he attributed meaning to the hexagram itself-significantly autonomous from his own interpretation. When we noted Jung's discourse in this regard, we did not resolve the concerns with agency and meaning once and for all. Rather, we were just preserving them against a premature resolution. The time now seems ripe to revisit them.

As one key to understanding Luhmann's systems theory, Habermas points out that

Luhmann introduces a peculiar concept of "meaning." In doing so, he draws upon phenomenological descriptions by Husserl, for whom the meaning of a symbolic expression refers to an underlying intention; "intention" is a more primitive notion than "meaning." Correspondingly, Luhmann defines "meaning" prelinguistically as a referential context of actualizable possibilities that is related to the intentionality of experience and action. Meaning-processing or meaning-using systems are substituted for subjects capable of being self-conscious. (Habermas, 1985/1987, pp. 369-370)

This is understandable as another aspect of Luhmann's systematic anti-humanism. The response from Habermas is not to appeal back to the classical humanism of the Kantian subject, but to counter with his own model of meaning and agency sustained in language and the communicative practices of the human social lifeworld.

While Habermas (who is informed by Peirce, especially via the work of K. O. Apel) restores suprasubjective meaning in the human world, Deely (2007) uses Peircean 
semiotics to account for suprasubjective intercourse among human and non-human beings in the world at large. In place of Husserl's one-way intentionality, by which the knowing subject is said to "constitute" the objects of cognition, Deely invokes an earlier conception of intentionality through which the things we know as objects simultaneously participate in the formation of our knowledge and experience through their own intentional expression as subjects of existence. Deely ties this to a concern with truth (which Habermas identifies as one casualty of Luhmann's universalistic systems theory):

The ability to be concerned with the truth is unique to the rational animal, predicated on the species-specifically human awareness of the objective world under the guise of being, transforming from the outset the animal Umwelt of objects ready-to-hand into an objective "life-world" of things present-at-hand, able to be investigated for what they are, the Lebenswelt of semiotic animals. (Deely, 2007, pp. 79-80)

Note that, on the one hand, Deely's non-Husserlian intentionality recuperates things in the world as subjects of their own existence, which we can know connaturally through the activity of triadic sign relations, while on the other hand he recognizes the unique capability of humans as uniquely semiotic animals (i.e., animals aware of signs as signs).

While I myself agree with Semetsky's reviewer in affirming the uniqueness of human being with regard to agency, assent to this position cannot be taken for granted in this context, since some forms of complex systems theory tend to dissolve the sense of human agency. In Luhmann's theory, for example, selves are subsystems processing information and behaving accordingly in the environment of other human and nonhuman subsystems. This tendency can also be seen in some forms of Actor-Network Theory (ANT), ${ }^{11}$ as derived from the work of Bruno Latour.

For an illustrative example of this issue, I will refer to an online discussion of Shaffer and Clinton (2006). The authors explain that "We focus in particular on how theories of mediated action, activity theory, and distributed cognition enable us to view thinking as an interaction between person and cultural tools" (Shaffer \& Clinton, 2006, p. 284). They find these theories unsatisfactory because, although the "focus shifts from studying the agent in isolation to studying the individual acting with tools, yet the agent still retains analytic primacy" (p. 284). In other words they fault these theories for treating persons as the agents of thinking.

"To address this issue," they tell us,

we draw ... from actor-network theory ... an understanding of action that views objects as agents in their own right-in which both humans and objects are actants that simultaneously act and mediate the actions of others. In this view, we cannot talk about tools (physical or symbolic) as mediators of thought, because to do so reestablishes a distinction between persons and artifacts. Instead, we argue, the status of human beings and objects as analytically equivalent actants requires creating a new category of toolforthoughts ... (p. 284)

\footnotetext{
${ }^{11}$ For one use of ANT in this journal, see Gough (2007).
} 
Noting that "all of these theories ... posit an asymmetrical relationship between persons and artifacts" (p. 288), they explain how they would fix this problem: "Positing symmetry between persons and artifacts means arguing that all activity is simultaneously internal and external, and that the processes involved are therefore not ontologically distinct ..." (p. 290).

Concerns and issues surrounding agency are reflected in these excerpts from an online discussion of that article. On June 26, 2007, Martin Packer wrote: ${ }^{12}$

Some quick thoughts...

The "premise that persons and artifacts are equivalent actants" might be viewed as the triumph of scientistic, materialist reductionism, no? People are just soft machines, after all. And the insistence that "there is no thinking without tools" is a wonderful limitation of thinking to no more [than] instrumental calculation.

And what better way to ensure that people really are no more than soft machines, extensions of technology, than to deny them access to the literacies that, one might argue, offer the possibility for freedom, for a different kind of thinking that steps out of "the system," at least for a moment.

What do you think? Do you think?

Martin

While the question "What do you think?" often appears at the end of posts on this discussion list, Martin Packer follows, this time, with the question "Do you think?" - a reminder that the stakes involved include whether you can claim to be the agent of the thinking.

On June 30, Jay Lemke responded, ${ }^{13}$

More likely, the analogy with Latour's position is that artifacts are more like people than we imagined before, though actually I think the point is that people are not people without their artifacts (and vice versa in some sense).

So what kinds of artifacts make us what kinds of people? and what kinds of artifactmediated literacies will make people in the future the kinds of people they want to be? perhaps not the same kinds of literacies that made the kinds of people there were in the past ... but the choice ought to belong to those who will be these people in the future, and I'm for supporting some new ways of being human.

JAY.

I chimed in later on June 30:14

\footnotetext{
${ }^{12}$ Archived at http://lchc.ucsd.edu/mca/Mail/xmcamail.2007_06.dir/0208.html. The XMCA (eXtended Mind, Culture, and Activity) email discussion list is an extension of the Mind, Culture, and Activity journal community, and is hosted by the Laboratory of Comparative Human Cognition at the University of California - San Diego. A new database for the online archives is being developed in 2008. If this thread becomes unavailable at the URLs in this and the next two footnotes, it will be retrievable from the search function at http://lchc.ucsd.edu/ .

${ }_{13}^{13}$ Archived at http://lchc.ucsd.edu/mca/Mail/xmcamail.2007_06.dir/0335.html .

${ }^{14}$ Archived at http://lchc.ucsd.edu/mca/Mail/xmcamail.2007_06.dir/0337.html .
} 
I think Jay reframes things well, and many of us would agree with the general position he expresses.

At the same time, I think his formulation reflects the limitations of the idea of symmetry - or maybe why symmetry should not be taken too literally, or too far.

Jay asks: what kinds of artifact-mediated literacies will make people in the future the kinds of people they want to be?

A symmetric paraphrase might read:

what kinds of people-mediated artifact-capabilities will make artifacts in the future the kinds of artifacts they want to be?

Appreciating [Wolff-Michael Roth's] issue with Heidegger ..., I think this does illustrate $\mathrm{H}^{\prime} \mathrm{s}$ point that Dasein is special, in being that Being for which its own Being is problematic. I don't know how someone would claim that artifacts are concerned in the same way with the existential question of what kinds of artifacts they "want to be" in the future. Of course artifacts can have auto-poietic or auto-telic powers, but there would not be the same kind of existential question for them as there is for us ...

The point is obviously not to seek any resolution of such issues here. The point for now is simply to be mindful that such issues are presented in the discourses we are dealing with. We can agree among ourselves, by stipulation, that we will treat things such as meaning and agency by regarding them in the senses most congenial to the prior understandings that we are most comfortable with. Doing so, however, would be at the cost of not hearing the discordant views of Jung (or of the I Ching itself), and of others voicing outlooks that are different from our own. And to do that would be to deny ourselves the complicated conversation that curriculum discourse deserves to be.

\section{Theoretical Altitude, and the Depth of Conversation}

Habermas (1985/1987) notes, almost in passing, that "The fact that Luhmann draws upon the reflective content of these two opposed traditions and brings motifs from Kant and Nietzsche together in a cybernetic language game indicates the level at which he establishes social systems theory" (p. 354). Luhmann synthesizes disparate theoretical and philosophical traditions at such a high altitude that we can't help losing site of how those discourses differ with each other. Instead of seeing this as a problem with Luhmann, in particular, we might be better served by seeing this as a cautionary example of what can happen in any such pansynthetic project in which a seamless discourse is woven from so many different fibers. ${ }^{15}$

When language from one theorist is grafted onto another discourse which that theorist would reject, is the original meaning of that language preserved in a contribution to the latter discourse? Or does the language take on a different meaning in

\footnotetext{
${ }^{15}$ Hut (1999) stands as an example of a contrary practice. In his "comparison ... of three approaches to an understanding of 'what is actual': modern science, Husserlian phenomenology, and Tibetan Buddhist Dzog Chen" (p. 391), he makes no effort to try to blend or reconcile these three approaches, but instead is interested in studying them as approaches that begin with three starkly differing conceptions of actuality.
} 
the new discourse? And, do we risk not hearing what the first theorist might have to say about the latter discourse, or what fruitful questions might arise from consideration of the differences between those discourses?

Semetsky relates how Noddings and Shore (1984) explain that

The four aspects characterizing the intuitive modes involve an almost immediate contact with object when the subject becomes affected or seized by the object. This requires a tension between certainty and uncertainty at both subjective and objective levels, as well as commitment and receptivity, that is, letting the object act upon the subject. (Semetsky, 2008, p. 69)

It sounds to me like what they're analyzing is the situation Deely would describe as one in which the thing encountered as an object for cognition is allowed to act upon the cognizing subject - to act, that is, as the subject of its own existence and activity, even as it informs the cognition of the other subject who will come to know it as an object of cognition.

While it does sound like that to me, I must resist being too hasty in assimilating Noddings to the discourse that I've learned from Deely. Maybe Noddings has more to say that I'll miss out on if I'm not looking for how she might be saying something that's not reconcilable with Deely. A similar caution prods me to wonder whether Noddings would recognize the "inner eye" she wrote about as the same organ involved in the process Jung describes (cf. Semetsky, p. 69).

Semetsky marshals a vast panoply of disparate thinkers to the service of her ambitious project. Many (including, for example, Herbert Simon) are not likely to endorse the project overall, and would surely reject great parts of it. That doesn't mean that the ideas which Semetsky takes from them cannot be coherently incorporated into her broad synthesis. ${ }^{16}$ It still may be worth considering, however, how respected sources might differ with the discourse in which they're being used-for the sake of the "complicated conversation," even if for nothing else.

And the possibilities for complicated conversation opened up by Semetsky's project are truly vast, indeed.

\footnotetext{
${ }^{16}$ For example, Stapp (2007) devotes a paragraph to Dennett's refusal to go along with Stapp's approach to quantum uncertainty and the "deeper reality" for which Semetsky is quoting Stapp in footnote 9 of her page 76. Semetsky cited Dennett on her page 64 as follows:

The archetypes may be considered memes (called such in contemporary philosophy of consciousness discourse), that is, complex ideas or habitual patterns that replicate themselves as they pass on via culture and communication in human actions and history (cf. Dennett 1991).

Although Dennett would not subscribe to the Jung, Pauli, and Stapp view of what I'm calling "hypermundane" reality, I think the idea of archetypes as memes is one that he would entertain. In any case, Semetsky's "cf." citation is careful in offering Dennett as a reference on "memes," without implying anything about his view of archetypes.

This being noted, readers unfamiliar with the range of thinkers that Semetsky has drawn into this paper might be forgiven if they come away with the impression that there is more of a convergence of views around positions taken here than is actually the case.
} 


\section{References}

Arntz, W., Chasse, B., Hoffman, M., \& Vicente, M. (2004). What the \#\$*! do we (k)now!? Yelm, WA: Lord of the Wind Films.

Arntz, W., Chasse, B., \& Vicente, M. (2005). What the bleep do we know!?: Discovering the endless possibilities for altering your everyday reality. Deerfield Beach, FL: Health Communications.

Bains, P. (2006). The primacy of semiosis: An ontology of relations. Toronto: University of Toronto Press.

Buck, J.A., Dent, E.B., \& Umpleby, S.A. (2000). Commentary: Communicating science-The difficulty introduced by the historical politics of the English language. Science Communication, 22(1), 73-87.

Byrne, R. (2006). The secret. New York: Atria Books.

Classic of Changes (The): A new translation of the I Ching as interpreted by Wang Bi. (1994). (R. Lynn, Trans.). New York: Columbia University Press.

Deely, J. N. (2001). Four ages of understanding: The first postmodern survey of philosophy from ancient times to the turn of the twenty-first century. Toronto: University of Toronto Press.

Deely, J. N. (2003). The impact on philosophy of semiotics: the quasi-error of the external world with a dialogue between $a$ 'semiotist' and a 'realist'. South Bend, IN: St. Augustine's Press.

Deely, J. N. (2007). Intentionality and semiotics: A story of mutual fecundation. Scranton: University of Scranton Press.

Deely, J. N., Petrilli, S., \& Ponzio, A. (2005). The semiotic animal. New York: Legas.

Dennett, D. C. (1991). Consciousness explained. Boston: Little, Brown and Co.

Dewey, J. (1934). Religion versus the religious, From A common faith. In Hickman, L. and T. Alexander (Eds.), The essential Dewey (1998), Vol. 1. Pragmatism, education, democracy (pp. 401-410). Bloomington: Indiana University Press.

Dewey, J. (1949). Common sense and science. In J. Dewey \& A. F. Bentley (Eds.), Knowing and the known (pp. 185-190). Boston: Beacon Press.

Dewey, J. (1998). How we think: a restatement of the relation of reflective thinking to the educative process. Boston: Houghton Mifflin. (Original work published 1933)

Gell-Mann, M. (1994). The quark and the jaguar: Adventures in the simple and the complex. New York: H. Holt (W.H. Freeman/Owl).

Gell-Mann, M., \& Mishlove, J. (1998). The Quantum and the quasi-classical: Jeffrey Mishlove interviews Murray Gell-Mann. Retrieved June 18, 2008, from http://www.williamjames.com/transcripts/gell1.htm

Gough, N. (2007). Rhizosemiotic play and the generativity of fiction. Complicity: An International Journal of Complexity and Education, 4(1), 119-124.

Habermas, J. (1987). The philosophical discourse of modernity: Twelve lectures. Cambridge, MA: MIT Press. (Original work published 1985)

Hut, P. (1999). Exploring actuality through experiment and experience. In S. R. Hameroff, A. W. Kaszniak \& D. J. Chalmers (Eds.), Toward a science of consciousness III: The third Tucson discussions and debates (pp. 391-405). Cambridge, MA: MIT Press. Also available at http://www.husserl.info/modules.php?name=News\&file=article\&sid=30

Jung, C. G. (1960). The structure and dynamics of the psyche. New York: Pantheon Books.

Jung, C. G. (1967). Foreword. In The I Ching; or, Book of changes. The Richard Wilhelm translation rendered into English by Cary F. Baynes. 3rd ed., pp. xxi-xxxix). Princeton, NJ: Princeton University Press. (Original work published 1950)

Luhmann, N. (1984). Soziale systeme: grundriss einer allgemeinen theorie. Frankfurt: Suhrkamp.

Main, R. (1997). Introduction. In C. G. Jung \& R. Main, Jung on synchronicity and the paranormal (pp. 144). London: Routledge.

Noddings, N. and Shore, P. (1984). The awakening of the inner eye: Intuition in education. New York and London: Teachers College Press. 
Pinar, W. F. (2004). "Possibly being so": Curriculum as complicated conversation. In W. F. Pinar, What is curriculum theory? (pp. 185-201). Mahwah, NJ: L. Erlbaum Associates.

Samuels. A. (1985). Jung and the post-Jungians. London and New York: Routledge.

Semetsky, I. (2008). Simplifying complexity: Know thyself ... and others. Complicity: An International Journal of Complexity and Education, 5(1), 63-79.

Shaffer, D. W., \& Clinton, K. A. (2006). Toolforthoughts: Reexamining thinking in the digital age. Mind, Culture, and Activity, 13(4), 283 - 300.

Simon, H. A. (1995). Near decomposability and complexity: how a mind resides in a brain. In H. J. Morowitz \& J. L. Singer (Eds.), The mind, the brain, and complex adaptive systems; Santa Fe Institute Studies in the sciences of complexity (Vol. 22, pp. 25-43). Reading, MA: Addison-Wesley Pub. Co.

宋祚胤 [Song Zuoyin]. (2000). 周易 [Zhou yi] (Song Zuoyin Trans.). 长沙 [Changsha]: 岳麓书社 [Yue lu shu she].

Stapp, H. P. (2003). Mind, matter, and quantum mechanics (2nd ed.): Berlin: Springer.

Stapp, H. P. (2007). Mindful universe: Quantum mechanics and the participating observer. Berlin: Springer.

von Franz, M.-L. (1980). On divination and synchronicity: The psychology of meaningful chance. Toronto: Inner City Books.

Whitson, J. A. (2007). Education à la silhouette: The need for semiotically-informed curriculum consciousness. Semiotica, 164(1/4), 235-329.

Whitson, J. A. (in press-a). Beyond cybernetics, info-mation, and cognitivism. Mind, culture, and activity.

Whitson, J. A. (in press-b). Decomposing curriculum, vs. curriculum-as-text. Journal of Curriculum and Pedagogy.

Wittgenstein, L. (2001). Philosophical investigations: The German text, with a revised English translation (G. E. M. Anscombe, Trans. 3rd ed.). Oxford: Blackwell. (Original work published 1953)

Wittgenstein, L. (2001). Tractatus logico-philosophicus (D. F. Pears \& B. F. McGuinness, Trans. Routledge Classics ed.). London: Routledge. (Original work published 1921)

Zabriskie, B. (2001). Jung and Pauli: A meeting of rare minds. In C. A. Meier (Ed.), Atom and archetype: the Pauli/Jung letters, 1932-1958 (pp. xxvii-1): Princeton, NJ: Princeton University Press.

\section{About the Author}

Tony Whitson is an Associate Professor in the School of Education at the University of Delaware. He is the author of Constitution and Curriculum: Hermeneutical Semiotics of Cases and Controversies in Education, Law, and Social Science (1991: Falmer), and with David Kirshner he co-edited Situated Cognition: Social, Semiotic, and Psychological Perspectives (1997: Erlbaum). Recent publications include Education à la Silhouette: The need for semiotically-informed curriculum consciousness. Semiotica, 164(1/4), 235-329 (2007). He blogs on curriculum matters at http://curricublog.org , and maintains a wiki on curriculum matters at http://tw-curricuwiki.wikispaces.com/ .

(c) Copyright 2008. The author, JAMES ANTHONY WHITSON, assigns to the University of Alberta and other educational and nonprofit institutions a non-exclusive license to use this document for personal use and in courses of instruction provided that the article is used in full and this copyright statement is reproduced. The authors also grant a non-exclusive license to the University of Alberta to publish this document in full on the World Wide Web, and for the document to be published on mirrors on the World Wide Web. Any other usage is prohibited without the express permission of the author. 